\title{
Elección tecnológica y expresión social: Análisis arqueométrico de cerámicas funerarias argáricas del Cerro de San Cristobal (Ogíjares, Granada)
}

\author{
Technological choice and social expression: Archaeometric analysis of \\ funerary argaric pottery vessels from Cerro de San Cristóbal (Ogíjares, \\ Granada)
}

\author{
Daniel Albero Santacreu*, Gonzalo Aranda Jiménez ${ }^{* *}$ \\ *Departamento de Ciencias Históricas y Teoría de las Artes, Universidad de las Islas Baleares, \\ Campus UIB, Ctra. Valldemossa km 7.5 s/n, 07122, Palma de Mallorca, Islas Baleares. \\ d.albero@uib.es \\ ** Departamento de Prehistoria y Arqueología, Universidad de Granada, \\ Campus Universitario de la Cartuja s/n, 18071, Granada, \\ garanda@ugr.es
}

Recibido: 26-09-2013

Aceptado: 25-11-2013

\begin{abstract}
RESUMEN
El estudio de las elecciones tecnológicas y el grado de variabilidad técnica observadas en la cerámica argárica se revela esencial para poder profundizar en las dinámicas sociales propias de la Edad del Bronce en el sureste peninsular. Desde esta perspectiva, el presente trabajo se centra en la caracterización arqueométrica de un conjunto de vasijas cerámicas procedentes de los contextos funerarios del Cerro de San Cristóbal (Ogíjares, Granada) con la finalidad de aproximarnos a sus pautas de fabricación, al grado de interacción de los artesano/as y al modo en que pudo organizarse la producción. Para ello, se ha procedido al análisis petrológico y mineralógico de las vasijas mediante microscopio petrográfico y Difracción de rayos $X$, y al estudio de la microestructura de la matriz arcillosa con microscopio electrónico de barrido. Los resultados evidencian una alta homogeneidad tecnológica en la mayor parte de piezas y tipos fabricados, excepto en algunas piezas tipológicamente diferenciadas de los estándares argáricos cuyos patrones de fabricación y deposición parecen responder a otras dinámicas sociales. Las elecciones tecnológicas constatadas evidencian un panorama complejo en el que pudieron interaccionar factores diversos como el habitus tecnológico, las estrategias de aprendizaje, el grado de interacción social y la forma en que las vasijas cerámicas fueron conceptualizadas.
\end{abstract}

Palabras Clave: Edad del Bronce, cerámica argárica, organización de la producción, especialización, variabilidad técnica, elección tecnológica, petrología, mineralogía.

\begin{abstract}
The study of the technological choices and the technical variability observed in the argaric pottery is essential to deepen in the social dynamics existing in southeast Iberia during the Bronze Age. From this perspective, this paper is focused on the archaeometric characterisation of a ceramic assemblage from the funerary contexts of Cerro San Cristobal (Ogijares, Granada) with the aim to approach the patterns of production, the interaction between the potters and the way in which the pottery production could be organised. To this end, we carried out the petrographic and mineralogical analysis of the vessels by means of petrographic microscope and X-ray diffraction as well as the study of the matrix microstructure through scanning electron microscopy. The results show significant technological homogeneity between most of the vessels and types produced, except for some ceramics which differ from the argaric typological standards whose technological choices and depositional patterns seem to be related to other social dynamics. The technological choices documented show a complex picture in which several aspects such as the technological habitus, the learning strategies, the social interaction and how the vessels were conceptualised are closely interconnected.
\end{abstract}

KEY WORDS: Bronze Age, argaric pottery, organisation of production, specialisation, technical variability, technological choice, petrology, mineralogy. 


\section{Introducción}

Las producciones cerámicas argáricas fueron consideradas desde el inicio de las investigaciones a finales del siglo XIX como uno de sus elementos culturales más característicos ya que suponían una clara ruptura respecto a los conjuntos cerámicos de las sociedades calcolíticas previas. Durante estos momentos, se generalizó un nuevo repertorio cerámico, con tendencia a presentar formas cerradas, de entre las que desatacan las vasijas carenadas y las típicas copas argáricas. Prácticamente desaparecieron las técnicas y motivos decorativos basados en la impresión e incisión, tan característicos de las cerámicas campaniformes o de las denominadas cerámicas "simbólicas". El bruñido de las superficies exteriores se convirtió en la nueva técnica decorativa, aplicada con especial esmero en las vasijas rituales, donde alcanza un brillo metálico intenso y llamativo. Las vasijas cerámicas pasaron a convertirse en uno de los elementos definitorios de "lo argárico".

Fueron los hermanos Siret (1890) quienes propusieron una primera ordenación tipológica a partir de los ajuares funerarios del asentamiento epónimo de El Argar. Definieron ocho tipos y tres subtipos utilizando como principal criterio el morfológico. A pesar de las inconsistencias y limitaciones de esta propuesta, por ejemplo, la no consideración de la cerámica procedente de contextos de hábitat, la mayoría de los/as investigadores/as posteriores la han asumido como la abstracción que mejor sintetiza la variabilidad formal de las cerámicas argáricas (Cuadrado 1950; Ruiz Gálvez 1977; Lull 1983; Van Berg 1998; Arteaga y Schubart 2000; Schumacher 2003; Jover y López Padilla 2009).

Peor suerte han corrido las discusiones en torno al valor cronológico de determinadas formas o rasgos cerámicos que a modo de "fósiles-directores" intentaban cualificar perspectivas teóricas coloniales y difusionistas que hacían depender cualquier cambio cultural de influencias externas. En las últimas décadas la discusión en torno a la cronología, al igual que el resto de aspectos culturales, ha estado intensamente marcada por posicionamientos autoctonistas. Así, la aparición de las cerámicas argáricas ha sido analizada en clave interna y su temporalidad fijada a partir de la cronología radiocarbónica, especialmente la obtenida en contextos funerarios (Castro et al. 1993-94).

A partir de los años 70, los nuevos posicionamientos teóricos de naturaleza funcionalista $\mathrm{y}$ materialista centraron su atención en explicar la aparición y consolidación de las primeras sociedades jerarquizadas. Dentro de esta nueva dinámi- ca, las vasijas cerámicas comenzaron a estudiarse como objetos resultado de un proceso productivo que era necesario caracterizar. La organización de la producción cerámica y su grado de especialización artesanal pasaron a convertirse en los nuevos objetivos de la investigación. La aproximación a este nuevo problema topó con la nula visibilidad arqueológica de los espacios en los que se manufacturó la cerámica y de los elementos que participaron en su producción, tanto herramientas como materias primas. Las únicas evidencias disponibles eran las propias cerámicas.

Esta importante limitación se ha tratado de superar midiendo el grado de estandarización de la cerámica argárica, asumiendo que un alto grado de homogeneidad se asociaría con unidades de producción limitadas y una regulación explicita del proceso productivo, frente a un alto grado de heterogeneidad que nos situaría ante un escenario más diversificado, con mayor número de productores, utilización de diferentes tipos de materias primas, menor destreza, ausencia de rutinas de producción o escaso control sobre la homogeneidad en los atributos de forma y tamaño. De esta forma, se procedió a analizar el grado de variabilidadhomogeneidad de los conjuntos cerámicos, bien para todo el ámbito argárico (Lull 1983), o bien para yacimientos específicos como Gatas, Fuente Álamo, La Bastida, Cuesta del Negro, Cerro de la Encina o Peñalosa. El procedimiento más habitual consistió en la aplicación de análisis estadísticos que permitieron la interrelación de diferentes variables métricas tomadas a partir de vasijas completas o potencialmente reconstruibles (Contreras et al. 1987-88; García López 1992; Van Berg 1998; Contreras y Cámara 2000; Aranda 2001, 2004, 2010).

El estudio de la variabilidad en otras variables tecnológicas no ha tenido, sin embargo, el mismo desarrollo. Muy al contrario, la aplicación de las numerosas técnicas de caracterización de materiales cerámicos actualmente disponibles ha sido muy limitada. Tras los pioneros trabajos de Josefa Capel Martínez sobre los conjuntos cerámicos de Cuesta del Negro (Contreras et al. 1987-88) apenas si se han realizado un par de nuevas aproximaciones, es el caso de los estudios de las cerámicas de Los Cipreses y Peñalosa (Milá Otero et al. 2000, 2007). Precisamente, es en este contexto donde se inserta el presente trabajo que tiene como objetivo general abordar el proceso de producción y la tecnología de la cerámica argárica a partir del estudio de las vasijas funerarias procedentes del asentamiento del Cerro de San Cristóbal (Aranda et al. 2012). Los objetivos particulares han consistido en la caracterización mineralógica, petrológica y de 
la micro-estructura de las pastas cerámicas como medio de aproximación al tipo y características de las materias primas utilizadas, a la estrategia seguida para la preparación de la pasta, al modelado de las cerámicas y a las estrategias de cocción, entre otros aspectos. De esta forma, se han tratado de definir las secuencias de producción (Rye 1981) presentes en este yacimiento como medio para aproximarnos a la conducta de los alfareros del pasado y relacionar los gestos tecnológicos constatados con el contexto en el que se insertan las cerámicas.

\section{Materiales y métodos}

\subsection{Contextualización arqueológica y geomor- fológica de las muestras analizadas}

El yacimiento del Cerro de San Cristóbal se localiza en plena Vega de Granada sobre una loma o pequeño altozano que en su punto más alto alcanza los $40 \mathrm{~m}$ de altura sobre la llanura aluvial (Fig. 1). Se trata de un pequeño poblado, de unas 0,6 ha de extensión, que se aleja del típico patrón de asentamiento argárico en cerros elevados y escarpados. $\mathrm{Su}$ localización en un entorno de suelos óptimos para el desarrollo de prácticas agrícolas lo aproxima a los denominados "poblados de llanura" entre los que destacan yacimientos recientemente investigados como Los Cipreses (Martínez Rodríguez et al. 1999) o El Rincón de Almendricos (Ayala Juan 1991). Las evidencias del hábitat son fragmentarias y aparecieron mal conservadas aunque con la suficiente entidad como para evidenciar la presencia de un asentamiento al que se asociaron, siguiendo el típico patrón argárico, 14 sepulturas, la mayoría de ellas en covacha aunque también se documentan inhumaciones en fosa y urna cerámica (Tabla 1) ${ }^{1}$.

Las vasijas analizadas en el presente trabajo han sido seleccionadas de entre los ajuares de estas sepulturas. En concreto, se han escogido 11 cerámicas representativas de la variabilidad formal registrada, donde destacan muy especialmente las formas carenadas. Todas las muestras pertenecen a los ajuares de 5 sepulturas a excepción de la única urna funeraria perteneciente a la sepultura 7 (Figs. 2 y 3$)$.

Desde una perspectiva geomorfológica, el yacimiento y su entorno se sitúan dentro del ámbito de la cordillera bética (IGME 1980). Los materiales que se constatan pueden dividirse según pertenezcan al conjunto alpujárride del Triásico en el que dominan litologías calizas o dolomíticas o bien a materiales detríticos postorogénicos del Neógeno

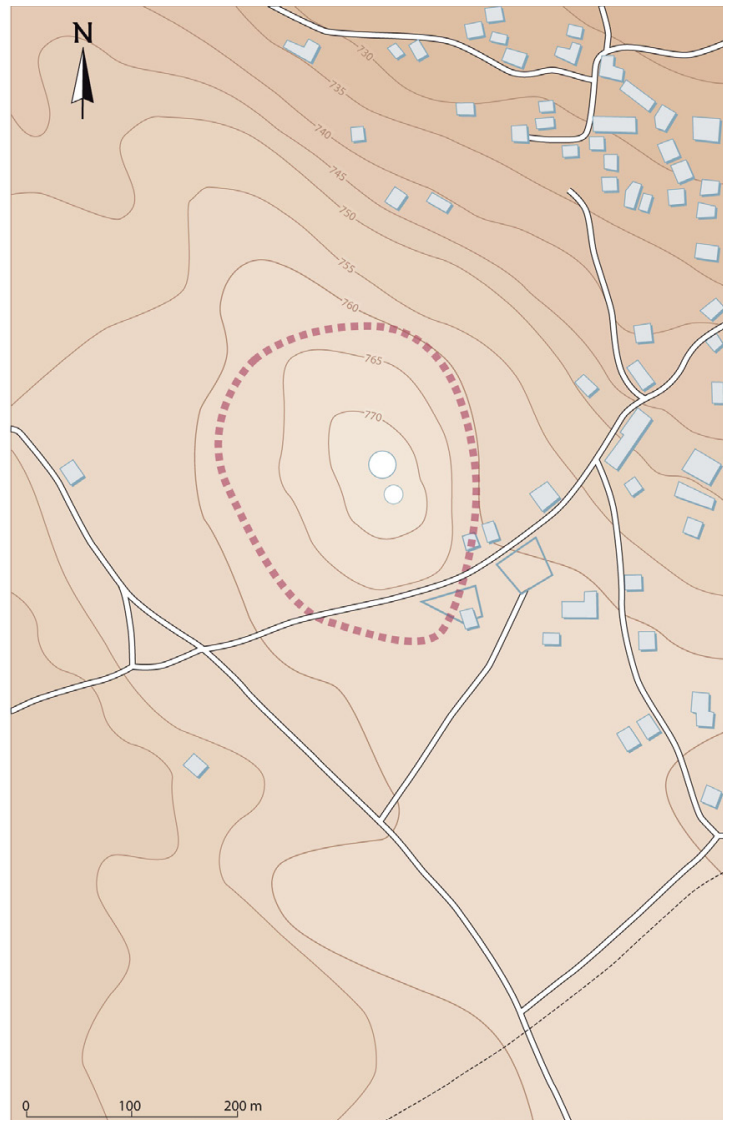

Figura 1.- Plano topográfico del yacimiento del Cerro de San Cristóbal.

y del Cuaternario. Son estos últimos los que predominan en la zona de estudio, aunque el conjunto alpujárride presenta también afloramientos extensos hacia el sur y sureste del yacimiento (Fig. 4).

Dentro del conjunto alpujárride hay diferentes unidades litoestratigráficas inferiores de tipo metamórfico formadas básicamente por metapelitas, micaesquistos y filitas que pueden presentar intercalaciones de cuarcitas. Frente a estas formaciones, la unidad superior, mucho más extensa que las anteriores, es de tipo carbonatada y está constituida por varios mantos formados básicamente por calizas y dolomías, en ocasiones con abundantes microfósiles, que pueden intercalarse con calcoesquistos. También se documenta la presencia de yesos y mármoles tableados.

Por su parte, los materiales postorogénicos son claramente discordantes con los anteriores y se asocian al relleno de la depresión de Granada. Entre los depósitos del Neógeno destacan calizas, calizas margosas, margas, biocalcarenitas, conglomerados, limos, arenas, areniscas, yesos y arcillas. Muchos de estos materiales (por ejemplo calizas y 


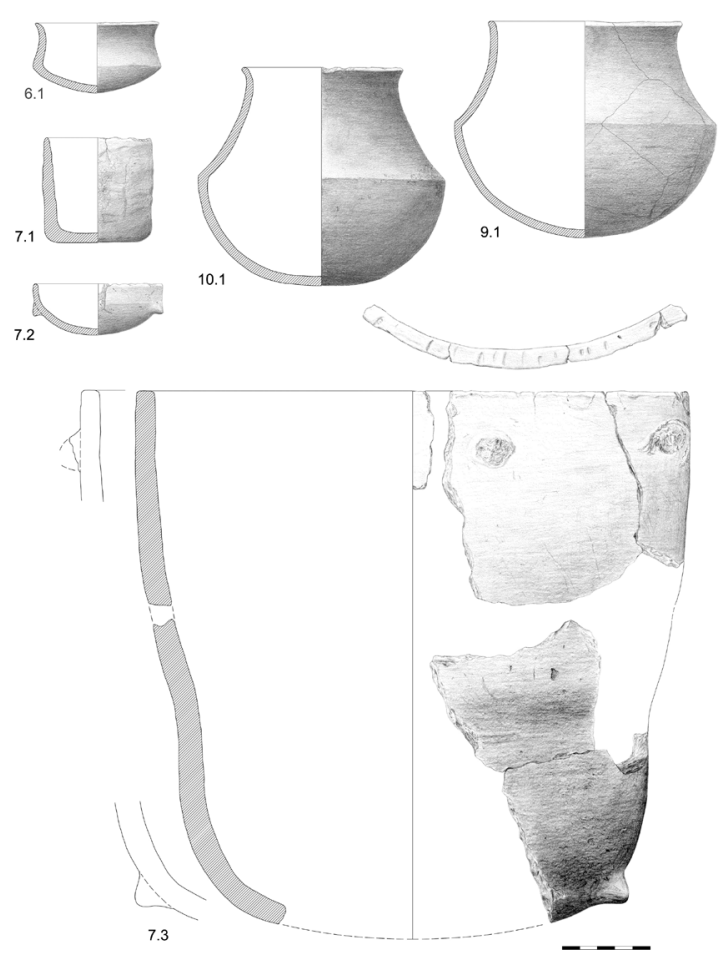

Figura 2.- Ajuar cerámico de las sepulturas 6, 7, 9 y 10. En la nomenclatura que acompaña a cada vasija el primer dígito pertenece al número de sepultura y el segundo al de pieza.

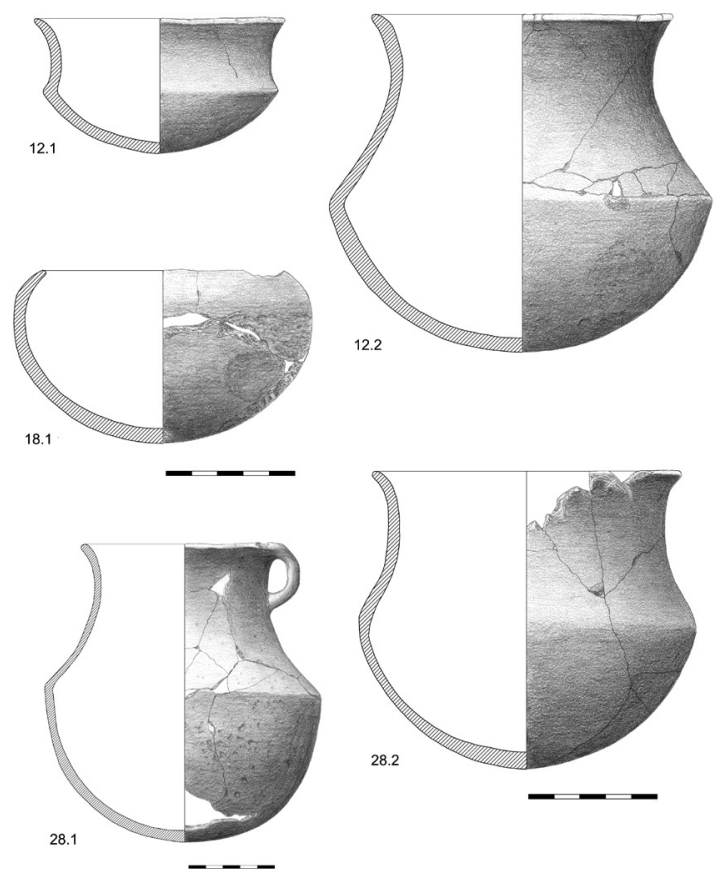

Figura 3.- Ajuar cerámico de las sepulturas 12,18 y 28. En la nomenclatura que acompaña a cada vasija el primer dígito pertenece al número de sepultura y el segundo al de pieza.

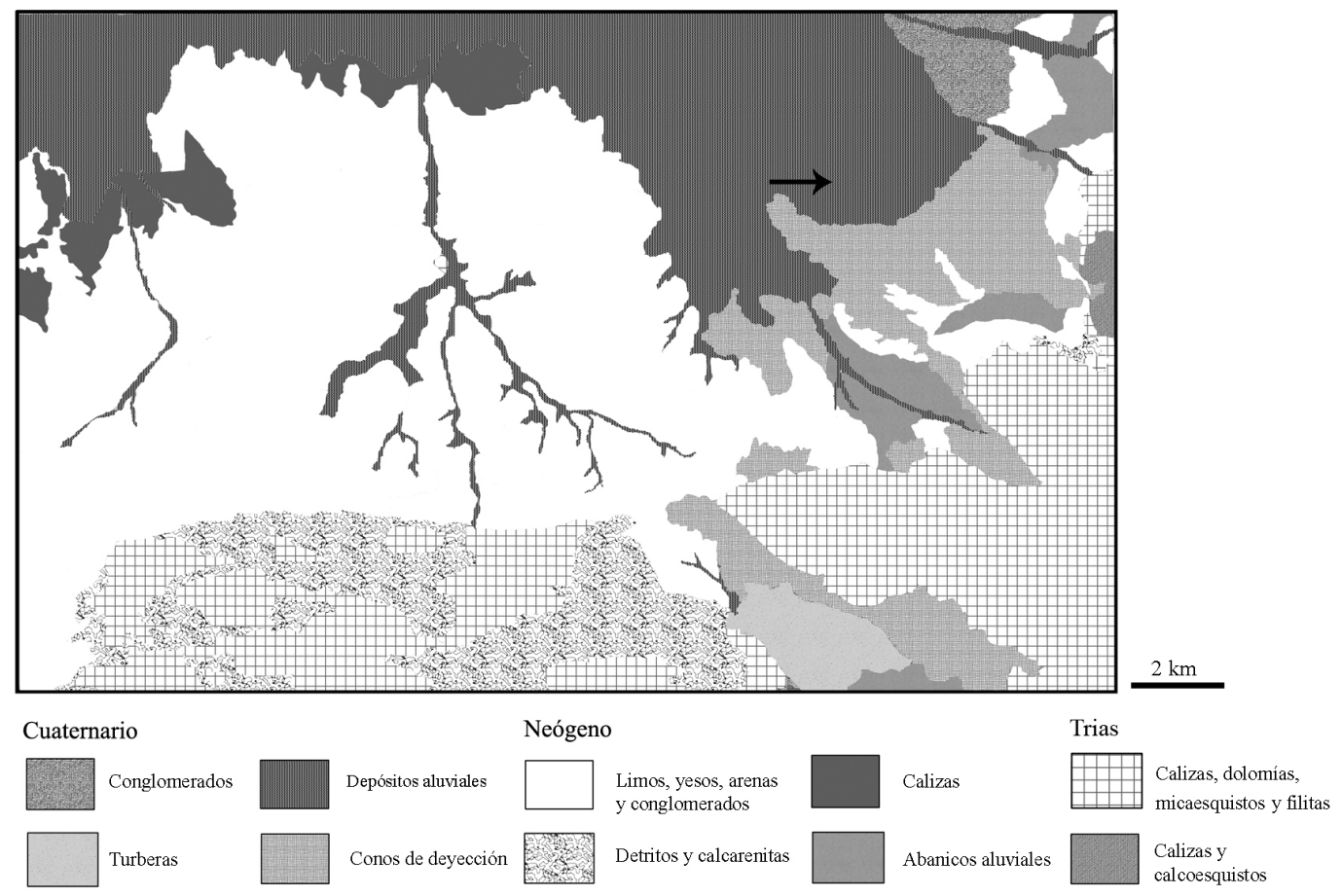

Figura 4.- Mapa geológico del entorno inmediato al yacimiento (simplificado a partir de IGME 1980). 


\begin{tabular}{|c|c|c|c|}
\hline $\begin{array}{l}\text { Número } \\
\text { sepultura }\end{array}$ & Tipo & $\begin{array}{c}\text { Inhumación/es } \\
\text { Sexo/Edad }\end{array}$ & Ajuares \\
\hline Sepultura 6 & Covacha & $1 \mathrm{~A} ?$ & 1pñ. C.; 1 br. B; 1 va \\
\hline Sepultura 7 & Urna & 1F-A 20-30Y; 1N 3-5Y & 1 pe. $B ; 1$ cn (hueso); 2 va \\
\hline Sepultura 8.1 & Fosa & $1 F-A$ & 4 re. $\mathrm{C}$ \\
\hline Sepultura 8.2 & Fosa & 1F-A 20-30Y & 1 pu. B; 4 cn (concha) \\
\hline Sepultura 8.3 & Fosa & $1 \mathrm{M}-\mathrm{A}$ & $1 \mathrm{va}$ \\
\hline Sepultura 8.4 & Fosa & $1 \mathrm{~F}$ & 1 lámina de metal; 1 cn (piedra) \\
\hline Sepultura 9 & Covacha & $?$ & 1pñ. C; 1va \\
\hline Sepultura 10 & Covacha & $1 \mathrm{~A} ?$ & 2 va. \\
\hline Sepultura 12 & Covacha & $1 \mathrm{M}-\mathrm{A} ; 1 \mathrm{~N} ?$ & 1pu. C; 1 pñ. C; 2 va \\
\hline Sepultura 17 & Covacha & $1 \mathrm{M}-\mathrm{A}$ & 1pñ. C; 83 barritas/clavos de Cobre \\
\hline Sepultura 18 & Covacha & $1 \mathrm{~F} ?$ & $2 \mathrm{va}$ \\
\hline Sepultura 28 & Fosa & $1 \mathrm{M} ; 1 \mathrm{~N}$ & $2 \mathrm{va}$ \\
\hline Sepultura 29 & Fosa & $1 \mathrm{~J}$ & Sin ajuar \\
\hline
\end{tabular}

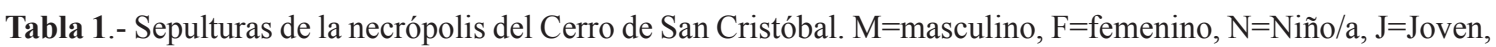
$\mathrm{A}=$ adulto, $\mathrm{Y}=$ año, $\mathrm{P}=$ Plata, $\mathrm{C}=$ cobre, $\mathrm{B}=$ Bronce, $\mathrm{br}=$ brazalete, $\mathrm{cn}=$ cuentas de collar, $\mathrm{p} \tilde{\mathrm{n}}=\mathrm{puñal} / \mathrm{cuchillo}$, $\mathrm{pe}=\mathrm{pen}-$ diente/anillo $\mathrm{pu}=$ punzón, $\mathrm{re}=$ remache, $\mathrm{va}=$ vasija cerámica.

margocalizas, limos, etc.) son de carácter lacustre por lo que pueden presentar abundantes microfósiles. Entre los materiales del Cuaternario señalar la presencia de abundantes conglomerados de origen diverso, areniscas, depósitos aluviales y turbas con arcillas y yesos.

\subsection{Métodos}

La metodología utilizada ha consistido en el análisis petrológico mediante microscopio de luz polarizada y lámina delgada (LD). En nueve muestras se ha analizado también la composición mineralógica mediante Difracción de rayos X (DRX) y se ha realizado, igualmente, un estudio de la microestructura de la matriz mediante microscopio electrónico de barrido (MEB).

El análisis mineralógico fue realizado mediante microscopio petrográfico. Para ello, se realizaron ${ }^{2}$ láminas delgadas perpendiculares a la superficie de las vasijas que fueron montadas y pulidas hasta obtener un grosor inferior a $30 \mu \mathrm{m}$. Se usó un microscopio petrográfico Leica Leitz Laborlux 12 Pol $S$ con cámara incorporada para la toma de micrografías $^{3}$. Los objetivos utilizados han sido x1.6, $\mathrm{x} 2.5, \mathrm{x} 4, \mathrm{x} 10, \mathrm{x} 40$, que comprenden un rango entre 16 y 400 aumentos. Para el estudio granulométrico de la sección se incorporó al microscopio un micrómetro y para estimar el porcentaje de cada componente mineral observado en lámina delgada se emplearon tablas comparativas ampliamente utilizadas en los estudios petrológicos y texturales (Matthew et al. 1991). El procedimiento seguido en la caracterización y descripción de las láminas delgadas y el establecimiento de petrofábricas ha sido el generalizado por I. Whitbread (1995). En el caso de la descripción y el análisis de inclusiones arcillosas (textural feature concentrations: TFC), además de los criterios establecidos por este autor (Whitbread 1986), se han tenido en cuenta los estudios de N. Cuomo Di Caprio y S. Vaughan (1993).

La composición mineralógica fue estudiada también mediante Difracción de rayos X (DRX) empleando análisis de muestra total. Para homogeneizar el tamaño de partícula de la muestra, las cerámicas fueron molidas, primero manualmente en un mortero de ágata $\mathrm{y}$, posteriormente, reducidas a una fracción inferior a $10 \mu \mathrm{m}$ mediante un pulverizador Pulverizer Progressive exploration model 100 single phase $e^{4}$ Se ha utilizado un difractometro Siemens $D-5000^{5}$ (radio $=240 \mathrm{~mm}$ ) utilizando la radiación $\mathrm{K} d \operatorname{del~} \mathrm{Cu}(\lambda=1,5405 \AA)$ como eje incidente y un monocromador de gonio en el eje difractado. Las condiciones de trabajo han sido de $45 \mathrm{kV}$ y $40 \mathrm{~mA}$. Las medidas $\theta / 2 \theta$ se realizaron entre 3 y $70^{\circ} 2 \theta$ con un tiempo de $3 \mathrm{~s}$ para cada paso. Las evaluaciones de las fases cristalinas se efectuaron con los programas Eva y X-Powder utilizando las tablas de espaciados e intensidades del banco de datos del Joint Committee of Powder Diffraction Standards (JCPDS 1974, 2003). Para la estimación semi-cuantitativa de las fases se ha 


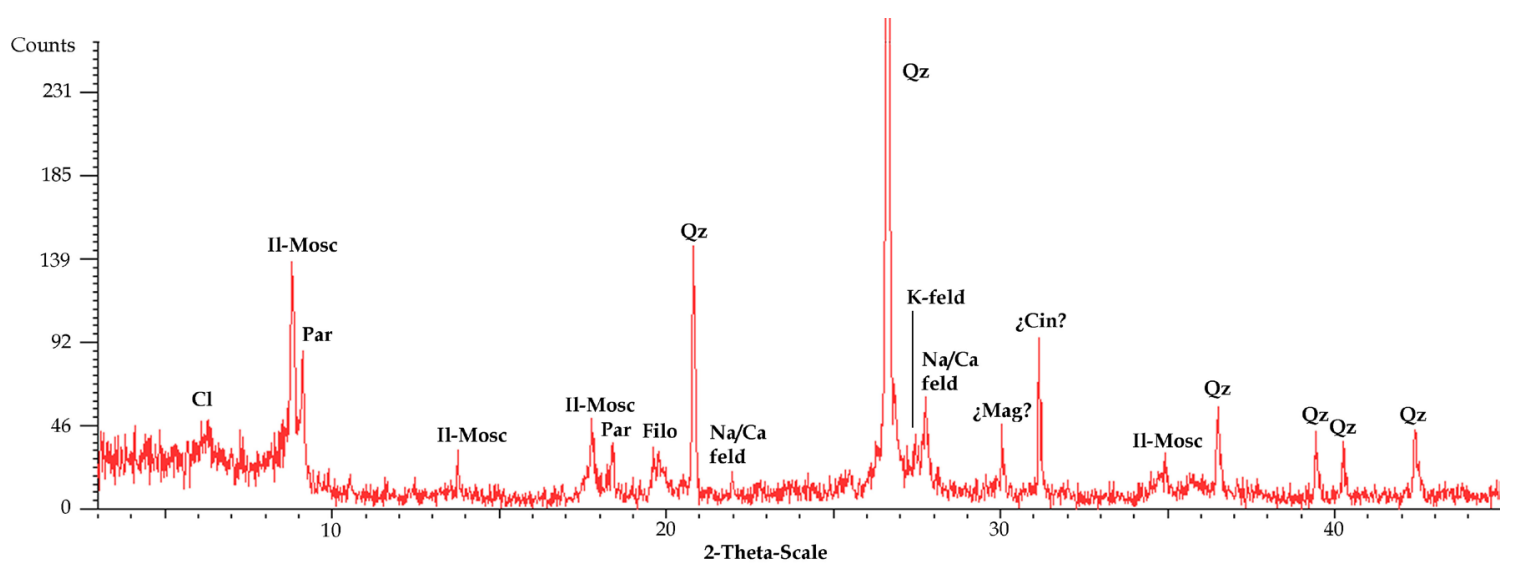

Figura 5.- Difractograma de rayos $X$ en muestra en polvo de la pieza CSC-28.1 mostrando las principales fases minerales identificadas en las cerámicas $(\mathrm{Cl}=$ Clorita; Il-Mosc $=$ Illita-Moscovita; Par $=$ Paragonita; Filo = Filosilicatos; Qz = Cuarzo; K-feld = Feldespato potásico; Na/Ca-feld = Plagioclasas; Cin = Cinabrio; Mag = Magnetita).

\begin{tabular}{|l|c|c|c|c|c|c|c|}
\hline Muestra & $\begin{array}{c}\% \\
\text { Illita }\end{array}$ & $\begin{array}{c}\% \\
\text { Moscovita }\end{array}$ & $\begin{array}{c}\% \\
\text { Paragonita }\end{array}$ & $\begin{array}{c}\% \\
\text { Cuarzo }\end{array}$ & $\begin{array}{c}\% \mathbf{K} \\
\text { Feldespato }\end{array}$ & $\begin{array}{c}\% \\
\text { Plagioclasas }\end{array}$ & $\begin{array}{c}\% \\
\text { Clorita }\end{array}$ \\
\hline C-14000 & 4,6 & 50,5 & 7,4 & 18 & 3,4 & 12,3 & 0,8 \\
\hline C-7003 & 3,6 & 38,6 & 7,7 & 15,9 & 16,9 & 13 & 0,8 \\
\hline C-11019 & 3,6 & 55,9 & 8,3 & 8,4 & 3,6 & 13,8 & - \\
\hline C-13000 & 6,5 & 54,3 & 2,7 & 15 & 11,2 & 4,6 & - \\
\hline C-11004 & 7,4 & 59 & 4,5 & 14,9 & 3,9 & 7,9 & - \\
\hline C-11003 & 6,2 & 55,5 & - & 5,8 & 19,1 & 7,2 & - \\
\hline C-30004 & 5,5 & 40,3 & 10,7 & 7,9 & 9,2 & 17,9 & - \\
\hline C-30003 & 5,7 & 47 & 6,1 & 9,9 & 10,3 & 10 & 1,1 \\
\hline C-15012 & 8 & 30,2 & 8,3 & 22,1 & 11,7 & 13,8 & - \\
\hline
\end{tabular}

Tabla 2.- Análisis semicuantitavo mediante el método RIR Normalizado de las fases minerales identificadas en las cerámicas con DRX.

utilizado el Método RIR (Reference Intensity $R a$ tios) normalizado (Chung 1974; Martín 2004).

Finalmente, se han analizado fragmentos de cerámica directamente sobre corte fresco para la observación de su microestructura y evaluar la posible presencia de una fase vítrea en las pastas. El grado de vitrificación se ha estudiado con microscopio electrónico de barrido (MEB) mediante imágenes a x2000 de las secciones cerámicas obtenidas a partir de electrones secundarios. Para ello, se ha utilizado un Hitachi S-3400-N Scanning Electron Microscope usando $15 \mathrm{kV}$ de tensión de trabajo $^{6}$.

\section{Resultados}

\subsection{Análisis de DRX}

Los difractogramas obtenidos del análisis de DRX (Fig. 5 y Tabla 2) evidencian que los principales minerales de la arcilla presentes en las muestras son la illita y la moscovita, destacando los picos de estas fases minerales a $10 \AA$ y $5 \AA$ por hallarse muy bien conservados. Además de estos minerales, excepto en la muestra CSC-7.2, también se ha identificado la presencia de paragonita $(9.70 \AA) \mathrm{y}$ de manera mucho más ocasional $(<3 \%)$ de clorita 
en los difractogramas de las muestras CSC-10.1, CSC-6.1 y CSC-28.1. En lo que se refiere a la fracción no plástica, en todas las muestras predominan el cuarzo y los feldespatos (potásicos y plagioclasas), probablemente microclina, ortoclasa y albita, como fases minerales principales dentro de la fracción gruesa. Los feldespatos son especialmente abundantes en algunas muestras como CSC-6.1, CSC-7.2 y CSC-28.2. Dentro de esta tendencia general, existen diferencias en función del predominio de feldespatos potásicos o plagioclasas.

También se ha documentado en varias muestras un codo en el pico principal de cuarzo a $3,36 \AA$ que podría corresponderse con grafito. En el caso de las vasijas CSC-7.3, CSC-18.1 y CSC-28.1 se observa un pico más o menos intenso a $2.86 \AA$, posiblemente cinabrio, y un pico a $2,97 \AA$ tal vez ligado a la presencia de magnetita. El cinabrio se presenta en las vetas de cuarzo, así como diseminado en las filitas, mientras la magnetita es un mineral metalífero también común en este tipo de roca que, como veremos a continuación, es la que ha podido identificarse principalmente en los estudios petrográficos. Por lo demás, las principales particularidades se relacionan con picos no identificados a $4,04 \AA$ y a $2,52 \AA$ en las muestras CSC12.2 y CSC-28.2 respectivamente.

\subsection{Análisis petrográfico}

El análisis petrográfico permite relacionar todas las muestras analizadas con una fábrica no-calcárea con abundantes rocas metamórficas, básicamente filitas $\mathrm{y}$, en menor medida, mica-esquistos (Fig. 6).

La micro-estructura de la pasta se caracteriza por la presencia de huecos distribuidos heterogéneamente por la matriz, pudiendo oscilar entre un $5-10 \%$. Los poros son mega-planares (relacionados con fibras de materia orgánica grafitizada de hasta $4 \mathrm{~mm}$ de longitud), mega-poros, macro-poros y meso-poros alongados e irregulares, así como micro-vesículas. Las inclusiones se distribuyen con un espaciado doble y simple, y los fragmentos de roca (especialmente los que presentan morfología alongada) se orientan de forma paralela a las paredes de la vasija, al igual que sucede con los poros.
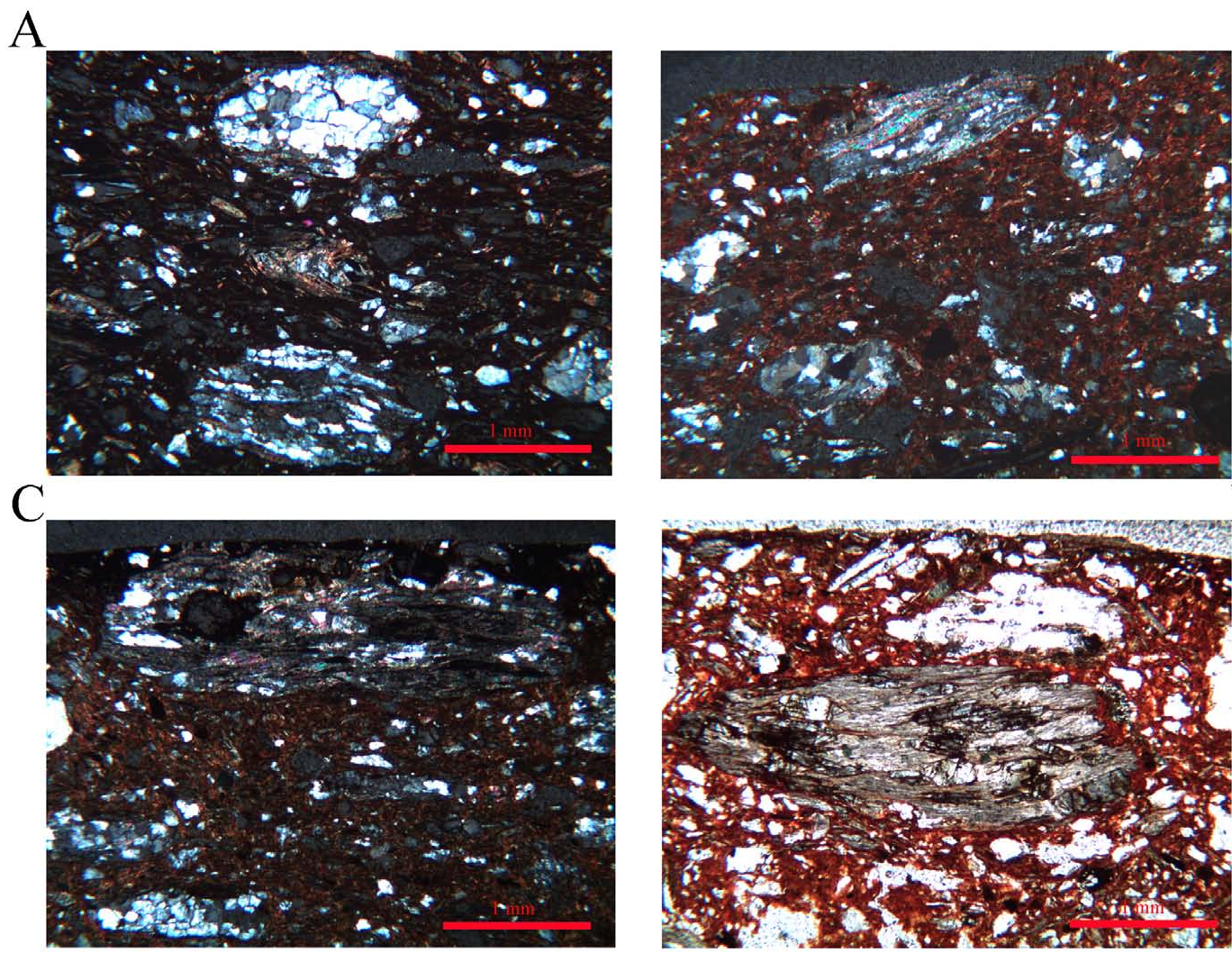

B

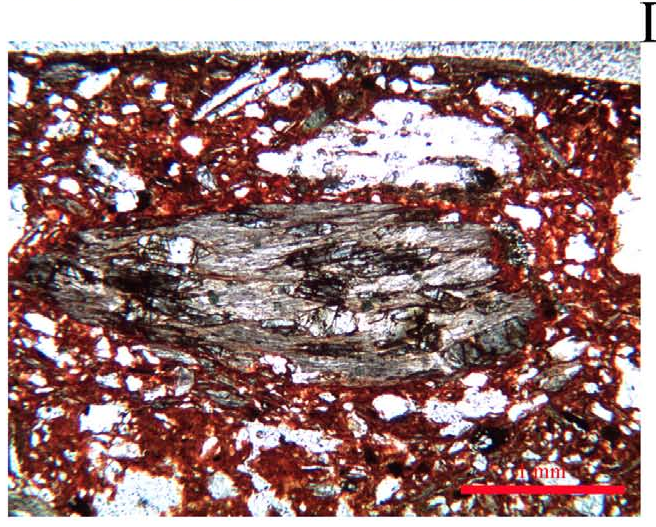

Figura 6.- Micrografías de láminas delgadas mostrando el aspecto típico de la fábrica con abundantes fragmentos de rocas metamórficas, cuarzo mono-cristalino y feldespatos. A) CSC-7.1 (nicoles cruzados). B) CSC-18.1 (nicoles cruzados). C) CSC-28.1 (nicoles cruzados). B) CSC-10.1 (luz plana). 
A

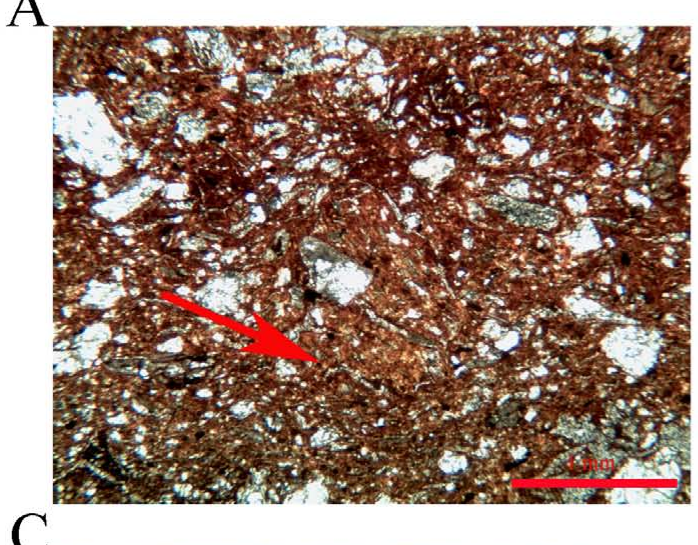

$\mathrm{C}$

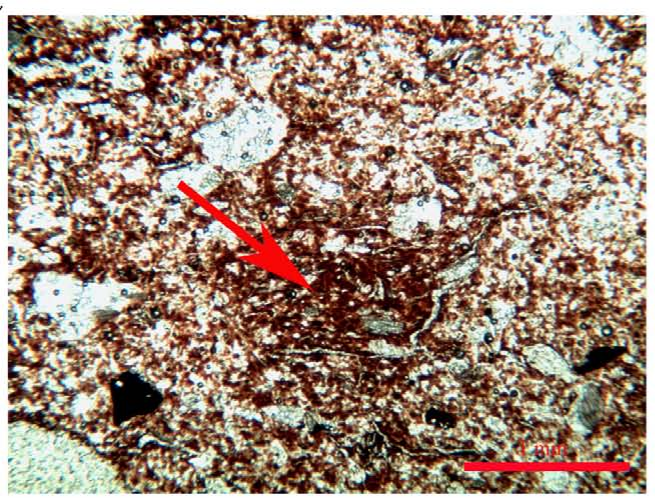

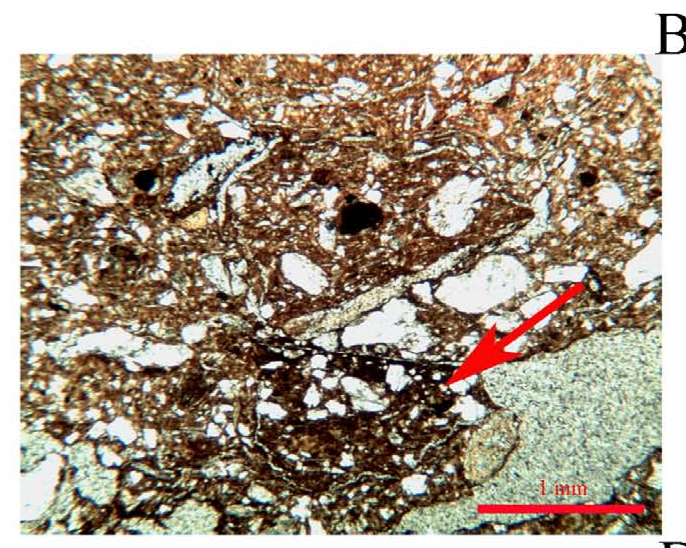

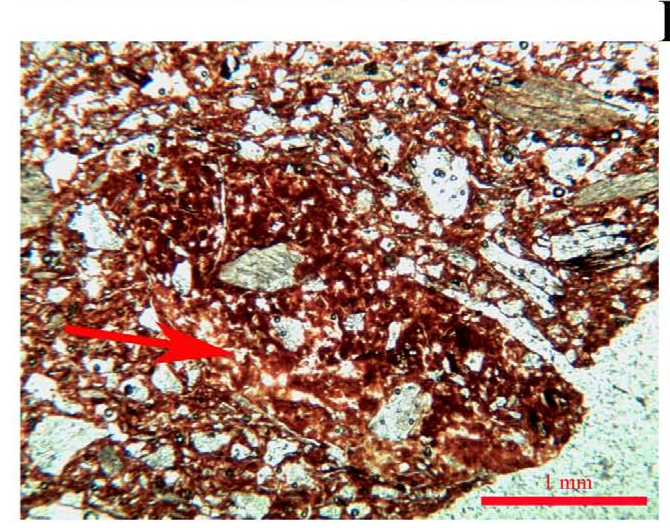

Figura 7.- Micrografías de láminas delgadas (luz plana) mostrando inclusiones arcillosas: A) Nódulo de arcilla en la pieza CSC-7.3. B) Fragmento de cerámica triturada en la pieza CSC-7.3. C) a) Nódulo de arcilla en la pieza CSC-7.1. D) Posible fragmento de cerámica triturada en CSC-6.1.

Las piezas presentan una rica matriz arcillosa (entre 65-85\%), no-calcárea y homogénea a lo largo de todas las secciones. Las principales variaciones entre las diferentes láminas se relacionan con la coloración de la matriz, la granulometría de las muestras y la cantidad de anti-plásticos (15$35 \%)$. La matriz varía entre ópticamente activa a moderadamente activa en la muestra CSC-9.1. Las matrices activas se relacionan todas ellas con una fábrica birrefregente salpicada-moteada (speckled $b$-fabric). El color oscila entre anaranjado/amarillento a marrón (luz plana, x400) y rojizo-marrón/ marrón oscuro (nicoles cruzados, $\mathrm{x} 400$ ).

Las inclusiones se presentan en una proporción gruesa/fina (hasta $10 \mu \mathrm{m}) /$ poros $\left(\mathrm{c}: \mathrm{f}_{10 \mu}: \mathrm{v}\right.$ ) que oscila entre 37:50:13 y 72:25:3. La fracción gruesa fluctúa entre $5 \mathrm{~mm}$ y $0,2 \mathrm{~mm}$ (de gravas a arenas finas) y la fracción fina es $<0,2 \mathrm{~mm}$ (arenas muy finas y limos). Las inclusiones están entre moderada y pobremente ordenadas y parecen tener una distribución bimodal en la que los fragmentos de rocas y minerales se insertan en una matriz con inclusiones más pequeñas.
Dentro de la fracción gruesa (Tabla 3) son abundantes los fragmentos de rocas como filitas, cuarcitas, meta-cuarcitas y mica-esquistos. De forma accesoria, en este sentido, se documentan fragmentos de pizarra en algunas muestras. Junto a las rocas citadas también destaca la presencia de cuarzo monocristalino y laminillas de moscovita, en menor medida, plagioclasas, feldespatos y cuarzo policristalino. Finalmente, se ha documentado la presencia escasa de biotita y rara vez epidota y amorfos opacos. En la fracción fina predominan los minerales observados en la fracción gruesa $\mathrm{y}$, en menor medida, se documentan cristales de clorita, epidota $y$, de forma accesoria, turmalina y estaurolita.

Generalmente, las muestras de esta fábrica no presentan concentraciones texturales (TFC). Las únicas observadas se relacionan con las siguientes vasijas:

La muestra CSC-7.3 presenta dos tipos de inclusiones arcillosas, unas apenas visibles (5\%) y otras claramente perceptibles (3\%). Las primeras (Fig. 7A) son equi-granulares/alargadas con los 


\begin{tabular}{|c|c|c|}
\hline \multirow{12}{*}{$\begin{array}{l}\text { Fracción } \\
\text { gruesa } \\
(\mathbf{7 0 - 4 0 \% )}\end{array}$} & Frecuente-Común & $\begin{array}{l}\text { Filitas: Fragmentos de roca de hasta } 1,8 \mathrm{~mm}(\text { moda }=1,5 \mathrm{~mm}) \text { con textura esquistosa } \\
\text { crenulada y plegada con un grado de alteración incipiente, compuestos básicamente } \\
\text { por cuarzo intercalado con laminillas de biotita y moscovita. }\end{array}$ \\
\hline & \multirow{4}{*}{ Común } & $\begin{array}{l}\text { Cuarcitas y meta-cuarcitas: }(<1,8 \mathrm{~mm} ; \text { moda }=1 \mathrm{~mm}) \text { fragmentos de rocas formadas } \\
\text { básicamente por cristales de cuarzo mono-cristalino alongados y deformados, sub- } \\
\text { redondeados con extinción recta y bien ordenados. }\end{array}$ \\
\hline & & $\begin{array}{l}\text { Cuarzo mono-cristalino: cristales alongados o equi-granulares de morfología angular } \\
\text { a redondeada con extinción recta }<3,2 \mathrm{~mm}(\text { moda }=1-0,5 \mathrm{~mm}) .\end{array}$ \\
\hline & & $\begin{array}{l}\text { Mica-esquistos: Fragmentos de roca de hasta } 5 \mathrm{~mm}(\operatorname{moda}=1,75 \mathrm{~mm}) \text { con morfología } \\
\text { alongada sub-angular o sub-redondeada y textura esquistosa muy fina, formados por } \\
\text { un inter-crecimiento de micas cloritas (especialmente en la muestra CSC-10.1), biotitas } \\
\text { (sobre todo en las muestras CSC-6.1 y CSC-28.1) y moscovitas con una crenulación } \\
\text { o disposición ondulada y presencia de micro-pliegues. En algunos casos, presentan } \\
\text { amorfos puros de forma alongada (probablemente grafito), intercalándose paralela- } \\
\text { mente entre las capas de micas. Las rocas poseen además algunos cristales de cuarzo y } \\
\text { plagioclasas y, de forma ocasional, epidotas y turmalina. }\end{array}$ \\
\hline & & Laminillas de moscovita (<1,2 mm; moda: $0,5 \mathrm{~mm})$. \\
\hline & \multirow{3}{*}{ Común-Escaso } & Cuarzo poli-cristalino: $(<1 \mathrm{~mm})$, cristales alongados sub-angulares. \\
\hline & & Plagioclasas: cristales sub-angulares, generalmente con maclado simple $(0,4 \mathrm{~mm})$. \\
\hline & & $\begin{array}{l}\text { Feldespato potásico: cristales alongados o equi-granulares de morfología sub-angular } \\
(\text { moda }=0,5 \mathrm{~mm}) .\end{array}$ \\
\hline & Escaso & Biotita $(<0,64 \mathrm{~mm})$ \\
\hline & \multirow[b]{2}{*}{ Raro } & Epidota: agregados $(<0,72 \mathrm{~mm})$ y cristales anhedrales aislados (moda: $0,3 \mathrm{~mm})$. \\
\hline & & $\begin{array}{l}\text { Amorfos (opacos): nódulos puros de redondeados a sub-angulares }(<2,4 \mathrm{~mm} \text {, moda }= \\
0,5 \mathrm{~mm}) .\end{array}$ \\
\hline & Muy raro-Ausente & $\begin{array}{l}\text { Pizarra (slate): fragmentos equi-granulares y redondeados }(<1,6 \mathrm{~mm} ; \text { moda }=0,4 \\
\mathrm{mm}) \text { documentados sólo en las muestras CSC-7.3, CSC-28.1 y CSC-28.2. }\end{array}$ \\
\hline \multirow{8}{*}{$\begin{array}{l}\text { Fracción } \\
\text { fina } \\
(\mathbf{5 0 - 2 5 \% )}\end{array}$} & \multirow{4}{*}{ Predominante } & Cuarzo mono-cristalino \\
\hline & & Laminillas de micas: moscovita, biotita \\
\hline & & Feldespato potásico \\
\hline & & Plagioclasas \\
\hline & \multirow{2}{*}{ Muy escaso } & Clorita \\
\hline & & Epidota \\
\hline & Raro & Turmalina \\
\hline & Muy raro & Estaurolita \\
\hline
\end{tabular}

Tabla 3.- Composición petrológica de las muestras cerámicas analizadas.

límites normalmente claros (aunque también pueden ser difusos) y morfología desde redondeada a sub-angular. Presentan unos rasgos concordantes en términos texturales con la matriz y con una densidad óptica entre alta y neutra. La matriz es ópticamente activa y las inclusiones no están orientadas. Todo surgiere que se trata de fragmentos de roca arcillosa y nódulos de arcilla. Las segundas (Fig. 7B), equi-granulares con límites y planos normalmente claros, poseen una morfología subangular, características afines a la textura de la matriz y una densidad óptica ligeramente más alta. $\mathrm{La}$ matriz es ópticamente activa y tanto ésta como las inclusiones que hay dentro del TFC se orientan pa- ralelamente a los extremos longitudinales. En este caso, se trataría de fragmentos de cerámica de la misma fábrica.

Las inclusiones de arcilla (3-5\%) de la muestra CSC-7.1 son apenas visibles, de $1 \mathrm{~mm}$ de moda en lo que se refiere a su longitud, alargadas o equigranulares con los límites claros y morfología redondeada, con una textura más fina que la de la matriz y con una alta densidad óptica en nicoles cruzados. La matriz es ópticamente activa y las inclusiones que hay dentro del TFC no están orientadas. Todo surgiere que se trata de nódulos de arcilla presentes de forma natural en la materia prima utilizada (Fig. 7C). 

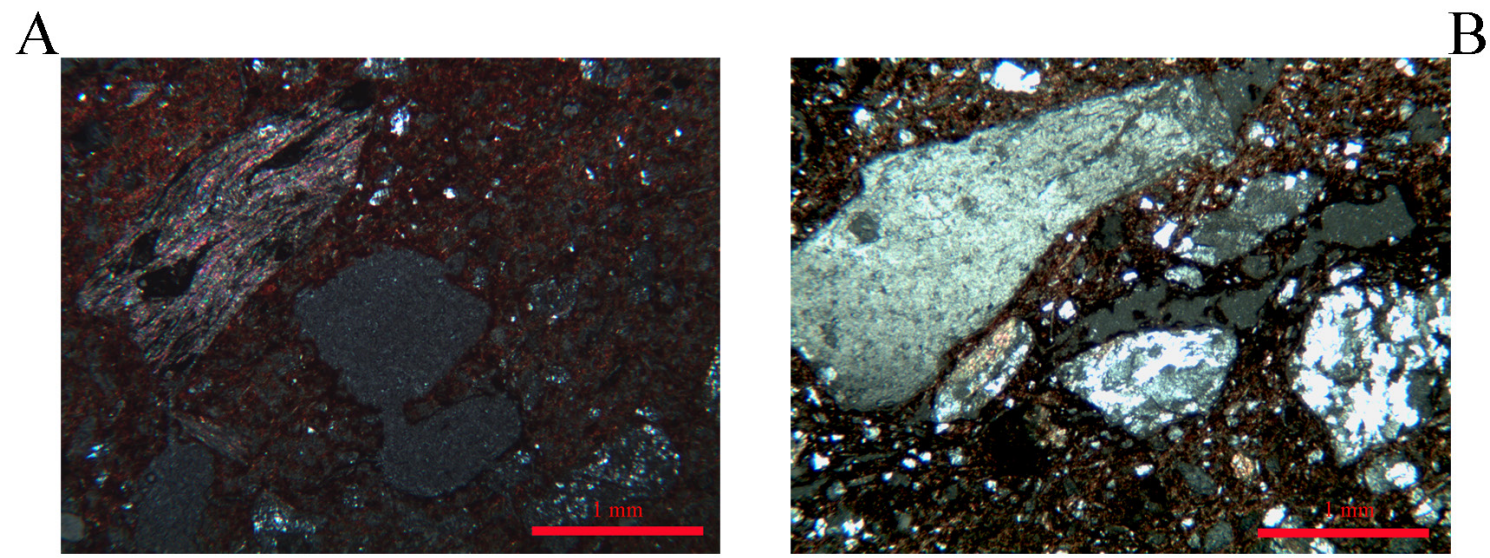

Figura 8.- Micrografías de láminas delgadas con nicoles cruzados mostrando A) una pasta muy fina en la pieza CSC7.1 y B) una pasta con una textura muy gruesa en la pieza CSC-7.3, ambas de la Sepultura 7.

Por último, la pieza CSC-6.1 presenta un sólo TFC $(<1 \%)$ de hasta $3,4 \mathrm{~mm}$, alargado y subredondeado con los límites bien definidos, rasgos análogos en términos texturales a la matriz y una alta densidad óptica. La matriz es ópticamente activa y su morfología y orientación sugieren que podría tratarse de un fragmento de chamota (cerámica triturada) asociado a una vasija de esta misma fábrica (Fig. 7D).

A modo de resumen, puede indicarse que los minerales y rocas observados en las muestras de esta fábrica se relacionan todos ellos con un entorno geomorfológico que presenta un grado de metamorfismo bajo vinculado a condiciones de baja presión y temperatura. La composición de las rocas y los minerales se relaciona básicamente con filitas y, en menor medida, con esquistos cuarcíticos y mica-esquistos como principales facies generadas a partir de la alteración de rocas sedimentarias pelíticas.

Dentro de esta fábrica existen algunas particularidades. Por ejemplo, la pieza CSC-9.1 se muestra muy rica en cuarzo (monocristalino y policristalino). La vasija CSC-6.1 posee mayor cantidad de micas que el resto de las piezas analizadas, especialmente en la fracción fina. Además, presenta una granulometría sub-milimétrica y las inclusiones mejor ordenadas que en otras muestras. La cerámica CSC-7.3 se caracteriza por presentar cristales de cuarzo mono-cristalino muy angulosos y más grandes que los observados en el resto de piezas de esta fábrica. Su textura gruesa con abundantes inclusiones (35\%) unida a la presencia de abundantes nódulos de arcilla surgiere el uso de una arcilla más heterogénea y basta. Por su parte, la pieza CSC-7.1 es de las que más se aleja de las características de esta fábrica ya que presenta una menor cantidad de inclusiones, $15 \%$ frente al 25 -
$35 \%$ del resto de muestras, algunas de ellas arcillosas y muy mal ordenadas.

En algunas muestras (CSC-18.1, CSC-7.1, CSC-7.2 y CSC-12.1) se han documentado restos de fibras alongadas y aisladas de materia orgánica parcialmente grafitizada que debieron formar parte de los depósitos de los que se extrajo la arcilla. También existen variaciones en el color de la matriz oscilando de unos tonos generalmente rojizos a otros menos usuales de color marrón (CSC-7.1 y CSC-7.3). Finalmente, señalar que algunas vasijas (CSC-18.1, CSC-7.1 y CSC-10.1) presentan en las superficies calcita micrítica secundaria completamente alóctona (Cau et al. 2002).

\section{Gestos técnicos}

\subsection{Obtención y preparación de la materia prima}

Las materias primas utilizadas en la producción cerámica son consistentes con el tipo de depósitos geológicos situados en el entorno más cercano al asentamiento $(<5 \mathrm{~km})$ asociados a formaciones metamórficas documentadas en el conjunto alpujárride. Todo indica que las arcillas pudieron proceder de cursos de agua como el del río Dílar, localizado a tan sólo $700 \mathrm{~m}$ del yacimiento, y cuyo trazado atraviesa depósitos geológicos en los que se observan los tipos de rocas documentados en las cerámicas (IGME 1980). Una estrategia similar de selección de materias primas arcillosas ricas en rocas metamórficas también parece ser la desarrollada por la población de Los Cipreses (Milá Otero et al. 2000), un asentamiento situado en un entorno de características parecidas al del Cerro de San Cristóbal. 
En cualquier caso, si bien el registro analizado debe asociarse en todas las muestras con el uso de depósitos arcillosos con gravas y arenas ricas en rocas metamórficas, existen algunas diferencias en lo que se refiere al tamaño de grano y el grado de homogeneidad de la arcilla (p. ej. CSC-6.1, CSC7.1 y CSC-7.3). Este aspecto unido a las variaciones constatadas en la coloración de las matrices sugiere que pudieron utilizarse diversos afloramientos que, como se expondrá a continuación, se relacionan con el tipo de piezas manufacturadas. De todos modos, hay que señalar que sin la realización de prospecciones y análisis arqueométricos de las materias primas disponibles en el entorno no se puede descartar que estas diferencias en la textura y la coloración de las pastas puedan deberse también a variaciones intra-depósito.

En todos los casos se trata de cerámicas no calcáreas, lo que sugiere, dada la amplia extensión que tienen los depósitos calcáreos en la zona, la selección de un tipo de recurso muy concreto de entre todos los disponibles en el área de captación del yacimiento. La mayoría de las muestras no presentan inclusiones arcillosas ni matrices abigarradas, evidenciando que no se han mezclado diferentes tipos de arcillas. En el caso de las escasas inclusiones arcillosas documentadas, al igual que la materia orgánica, deben relacionarse principalmente con su presencia de forma natural en los depósitos sedimentarios y con el uso de materias primas poco homogéneas para la fabricación de determinadas vasijas.

La cantidad alta de inclusiones observada en la mayoría de las muestras y la presencia de materia orgánica residual evidenciarían que las arcillas no han sido decantadas o cribadas y que no se han añadido desgrasantes. Fueron utilizadas, en la mayoría de los casos, tal y como se presentaban en el lecho aluvial del que fueron recogidas, realizándose, probablemente, sólo una limpieza superficial de aquellas inclusiones de mayor tamaño susceptibles de representar un riesgo para la producción.

Como se ha señalado, los principales anti-plásticos documentados en las muestras son fragmentos de rocas, cuarzos y feldespatos en una fracción bastante gruesa $($ moda $=1-1,5 \mathrm{~mm})$ y en cantidades altas, de modo que habrían contribuido a proporcionar una alta consistencia a la pasta durante el modelado y a disminuir su contracción durante el proceso de secado. Podemos suponer que la textura y los anti-plásticos minerales que las arcillas presentaban de partida eran suficientes para una producción exitosa. En este sentido, la inversión de esfuerzo dada la escasa distancia de las vetas de arcilla y el prácticamente nulo requerimiento para su preparación, salvo por la retirada de las gravas y de materia orgánica de mayor tamaño, haría muy rentable en términos economicistas y de mínimo esfuerzo la utilización de esta materia prima.

Como inclusiones de origen antrópico podemos apuntar únicamente a la presencia aislada de algunos fragmentos de chamota en las piezas CSC-6.1 y CSC-7.3. En cualquier caso, su escasa cantidad no permite asegurar una adición intencional con el objetivo de alterar las cualidades de la materia prima, no pudiéndose descartar que estas inclusiones se relacionen con fragmentos de chamota incorporados accidentalmente en el transcurso de la preparación de la pasta y/o el modelado de la pieza.

Dentro de este esquema general, algunas piezas presentan diferencias tecnológicas en relación a lo comentado anteriormente. Nos referimos, por ejemplo, a la pieza CSC-6.1, un vaso cerámico carenado de superficies bruñidas y con un brillo intenso que además de presentar algún fragmento de chamota en su pasta también muestra una matriz con menos cuarzo y más mica que el resto de piezas.

En otras vasijas las diferencias tecnológicas coinciden con ciertas particularidades tipológicas y/o cronológicas. Este es el caso de la muestra CSC-7.1, cuyas características formales, fondo plano, cuerpo cilíndrico, paredes gruesas y superficies alisadas e irregulares hacen que esta cerámica sea completamente ajena a las formas típicas de época argárica, especialmente de sus contextos funerarios. Como se ha señalado anteriormente, presenta una textura sub-milimétrica, sensiblemente más fina que la observada en el resto del conjunto estudiado (Fig. 8A), teniendo, además, una menor cantidad de inclusiones (15\%) mal ordenadas y algunos nódulos de arcilla.

Esta misma situación se documenta en la urna funeraria de la sepultura 7 correspondiente a la muestra CSC-7.3 (Fig. 8B). A las particularidades tecnológicas, textura gruesa, cristales de cuarzo muy angulosos de hasta $3 \mathrm{~mm}$, alto porcentaje de anti-plásticos (35\%) y abundantes nódulos de arcilla se suman unas características formales parecidas a las documentadas en otros yacimientos argáricos como Gatas (Colomer 2005), especialmente la irregularidad de sus paredes. Las propiedades tecnológicas y formales surgieren tanto el uso de una arcilla más heterogénea y peor homogeneizada que lo observado en el resto de cerámicas como unas habilidades más limitadas en su manufactura.

Finalmente, otra de las muestras que también presenta ciertas particularidades es la vasija CSC7.2 perteneciente igualmente al ajuar de la sepultura 7. En este caso, los rasgos tecnológicos distintivos como la ausencia de paragonita y las elevadas cantidades de feldespato potásico se asocian con 
un cuenco carenado y borde recto del que cuelgan a modo de decoración pequeños mamelones troncocónicos. Estas propiedades formales, tal y como se documenta en las secuencias estratigráficas de poblados como el Cerro de la Encina (Aranda 2001) o Fuente Álamo (Schubart et al. 2000), son características de un momento cronológico muy avanzado de El Argar, adquiriendo su máximo desarrollo ya en época posargárica.

En definitiva, el conjunto de cerámicas estudiado se caracteriza por la homogeneidad en el tipo y características de las materias primas utilizadas, así como en la estrategia de preparación de la pasta. En las vasijas que se alejan tecnológicamente de esta norma se produce una destacable coincidencia con propiedades formales alejadas de los estándares argáricos y con rasgos cronológicos específicos, pero sobre todo se trata de cerámicas contextualmente asociadas a la sepultura 7. Posteriormente, retomaremos esta discusión.

\subsection{Modelado y tratamiento de superficie}

En la mayor parte de las secciones estudiadas, se documenta una intensa presión sobre las paredes de la vasija durante el modelado, preparación de los rulos y posterior tratamiento de la superficie, lo que favoreció una orientación paralela a las superficies de la vasija de los fragmentos de roca y minerales presentes en la pasta. Con este tipo de acciones se facilitó una mejor deshidratación como consecuencia del hundimiento de las inclusiones más grandes en la pasta, facilitando así la evaporación del agua hacía los márgenes de la cerámica, reduciéndose, de esta forma, el agua contenida en los poros internos y el tiempo de secado (Capel et al. 1995; Velde y Druc 1999). En términos funcio- nales, este tipo de orientación de los anti-plásticos de morfología alongada paralela a las paredes de las piezas habría facilitado, además, la consecución de unas pastas más resistentes frente a la propagación de fracturas durante las fases de secado, cocción y uso (Schiffer y Skibo 1987).

En el caso concreto de la muestra CSC-7.3, se ha podido observar una orientación preferente de los desgrasantes en diagonal respecto a las paredes de la vasija formando un semicírculo que debe asociarse con el punto de unión de dos rulos o columbines (Fig. 9A). Por la posición de la muestra analizada se trata de la manufactura del borde de la pieza. Esta estrategia de modelado se correspondería con el Tipo B identificado por Colomer (2005) en el yacimiento de Gatas.

\subsection{Estrategia de cocción}

Las pastas documentadas se componen básicamente de una rica matriz arcillosa y micas, así como cuarzo y feldespatos en forma de gravas y arenas que aportan una alta cantidad de sílice, proporcionando un cuerpo cocido muy refractario. Las piezas analizadas no han presentado ningún desarrollo de fases de alta temperatura en los análisis de DRX, algo que suele ser usual en cerámicas prehistóricas muy silíceas y no calcáreas, ya que son menos susceptibles de presentar cambios en su micro-estructura derivados del proceso de calentamiento. Los principales anti-plásticos documentados son minerales muy resistentes y estables termométricamente en lo que se refiere a sus propiedades físicas, estando, al menos en el caso del cuarzo, las transformaciones mineralógicas directamente relacionadas con el tamaño del grano y la temperatura de cocción (Linares et al. 1983).
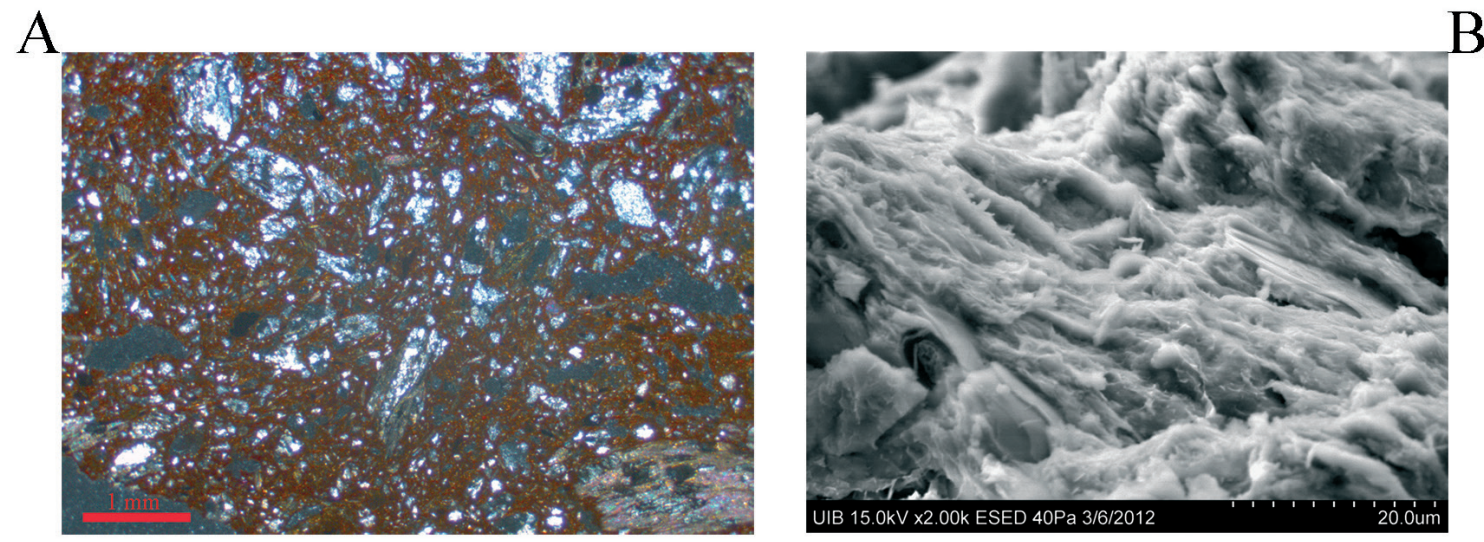

Figura 9.- A) Micrografía de una lámina delgada con nicoles cruzados mostrando la orientación de las inclusiones perpendicular y en diagonal respecto a las paredes de la vasija CSC-10.1. B) Micrografía obtenida con microscopio electrónico de barrido mostrando la estructura laminar de los filosilicatos de la pieza CSC-7.3 con una matriz sin vitrificar. 


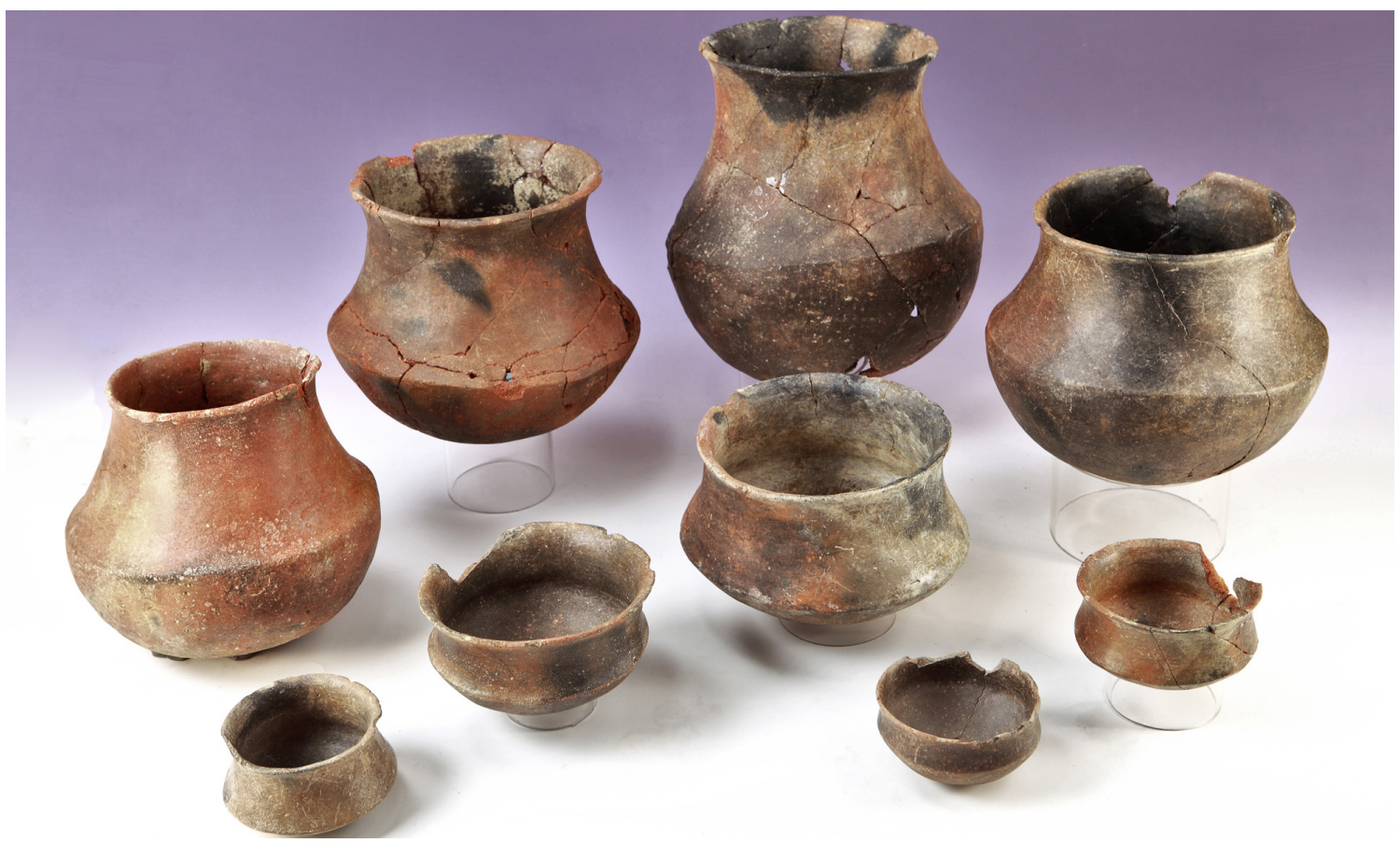

Figura 10.- Conjunto de vasijas carenadas procedentes de los ajuares funerarios del Cerro de San Cristóbal. Observar la coloración de las superficies heterogénea y la presencia de manchas aleatoriamente distribuidas.

Además de la ausencia de fases de alta temperatura, la permanencia de picos de filosilicatos muy bien conservados en los difractogramas de DRX supone una clara evidencia de cocciones a baja temperatura. Este es el caso de la presencia de picos secundarios de minerales de la arcilla como la illita-moscovita a $10 \AA \mathrm{y}$, especialmente, a $5 \AA$ (Fig. 5). A partir de $650^{\circ} \mathrm{C}$, el pico diagnóstico de la illita-moscovita presenta las primeras evidencias de alteración hasta su práctica desaparición a los $800{ }^{\circ} \mathrm{C}$ (Drebushchak et al. 2005; Buxeda y Tsantini 2009). De igual forma, la presencia de picos de paragonita evidenciaría la cocción cerámica a bajas temperaturas, pues su descomposición se produce entre los 580 y $700{ }^{\circ} \mathrm{C}$ (Comodi y Zanazzi 2000). Dentro del rango de temperatura 500/650 ${ }^{\circ} \mathrm{C}$ debemos situar también la descomposición de fases como la clorita (Maritan et al. 2007), que también ha sido identificada en varias muestras. En conclusión, las fases minerales detectadas evidencian que todas las vasijas analizadas presentan una temperatura de cocción inferior a los $700^{\circ} \mathrm{C}$.

Las observaciones de la microestructura de las piezas realizadas con SEM son igualmente consistentes con lo señalado hasta ahora. La matriz presenta láminas de minerales de la arcilla que no han sufrido ningún proceso de sinterización o vitrificación (Fig. 9B). Esta microestructura se corresponde con un estadio donde no hay vitrificación, lo que permite establecer una temperatura de cocción inferior a $800{ }^{\circ} \mathrm{C}$ (Mainman 1982; Buxeda y Madrid 2009). En definitiva, como ya se observó en otras producciones argáricas asociadas a contextos funerarios (Contreras et al. 1987-88; Milá Otero et al. 2007), las temperaturas de cocción estimadas para las cerámicas funerarias del Cerro de San Cristóbal deben considerarse bajas.

En lo que se refiere a la atmósfera de cocción, se observa como la mayoría de piezas se han cocido en ambientes oxidantes, si bien algunas muestras presentan procesos de reducción poco marcados en el margen interno (CSC-18.1, CSC-28.1, CSC28.2) y/o externo (CSC-7.1, CSC-9.1 y CSC-28.1). Como ya sucedía con su textura y granulometría, la urna funeraria (CSC-7.3) ha supuesto una excepción dentro de esta tendencia. Esta vasija, de gruesas paredes, muestra una atmósfera reductora en el margen interno y en el núcleo de la sección, sólo parte del margen externo presenta una transición abrupta asociada al uso de una atmósfera oxidante al final de la cocción. Estas diferencias pueden relacionarse con una estrategia de cocción específica para esta pieza. En cualquier caso, la inmensa mayoría de las vasijas funerarias poseen una coloración de sus superficies relativamente heterogénea y con manchas aleatoriamente distribuidas (Fig. 10). Ello permite plantear el uso de estructuras de combustión donde no existiría una 
conducción uniforme del aire y del calor y en las que las piezas estarían en contacto directo con el fuego (García Rosselló y Calvo 2006).

\section{Conclusiones}

Como se indicaba en la introducción del presente trabajo, la aproximación a las formas de producción de la cerámica argárica se había realizado básicamente desde el análisis de la estandarización de sus variables formales y en menor medida tecnológicas. En términos generales, el estudio realizado para el Cerro de San Cristóbal es coincidente con estos trabajos, destacando una secuencia de producción caracterizada por la alta homogeneidad de las materias primas utilizadas, de las técnicas de preparación de la pasta, así como en las fábricas obtenidas en términos de composición, textura y cualidades. También las estrategias de cocción con temperaturas bajas y/o tiempos de exposición cortos y el uso de atmósferas fundamentalmente oxidantes resultan muy homogéneos en prácticamente todo el conjunto analizado.

Ahora bien, este alto grado de homogeneidad en las soluciones técnicas ¿supone la presencia de formas de producción especializadas? Y si fuera así, ¿cuál sería el tipo y grado de especialización? La relación entre estandarización de la producción y especialización es ciertamente compleja. Aunque, efectivamente, esta relación aparece frecuentemente confirmada por trabajos arqueológicos y etnográficos (Sinopoli 1988; Blackman et al. 1993; Longacre 1999; Costin 2000), también es cierto que el grado de estandarización de las vasijas está condicionado por factores sociales, políticos o ideológicos en ocasiones ajenos al grado de especialización artesanal o a la eficiencia en la manufactura (Stark 1995; Arnold 1999, 2000; Neupert 2000).

Quizás, un buen punto de partida sea definir qué consideramos por especialización. C. Costin $(1991,2005)$ la define como un sistema regular y permanente de producción en el que los artesanos dependen de relaciones de intercambio supradomésticas, al menos para el desarrollo de parte sus actividades subsistenciales, y los consumidores necesitan adquirir los bienes que no producen. Para que una producción sea especializada se requiere, por tanto, que los consumidores no sean miembros de la misma unidad doméstica que los productores. Así, los elementos que definen la especialización artesanal son, por una parte, una escala e intensidad en la manufactura de determinados bienes que supere las propias necesidades tanto de productores como de su ámbito domésti- co, y por otra el disfrute de esos bienes por unos consumidores que no han participado en su elaboración pero que gracias a determinadas relaciones de intercambio (simétricas o asimétricas) son los beneficiarios últimos.

Esta definición implica una enorme variabilidad en cuanto a los tipos y grados de especialización potencialmente identificables. En el caso del Cerro de San Cristóbal la homogeneidad registrada en las propiedades tecnológicas de las vasijas funerarias permite platear la existencia de un perfil de alfarero relativamente especializado. En cualquier caso, se trataría de una especialización de baja intensidad, posiblemente realizada a tiempo parcial y de forma estacional, si tenemos en cuenta la ausencia de talleres cerámicos o de cualquier evidencia relacionada con el proceso de producción. Quizás, como apunta Colomer (2005), la forma de producción adoptada pudo aproximarse al tipo denominado como "industria doméstica" consistente en la especialización de sólo algunas unidades familiares en este proceso productivo.

$\mathrm{Si}$ consideramos las prácticas tecnológicas como parte de las complejas y dinámicas interacciones sociales que se dan en las comunidades en las que los objetos se fabrican y utilizan (Dobres y Hoffman 1994), conceptos como el de elección tecnológica (Lemmonier 1993), habitus tecnológico (Dietler y Herbich 1998), estrategia de aprendizaje (Budden 2009) y percepción de la materialidad (Hurcombe 2007) pueden ser ciertamente útiles en la compresión de las formas de producción y su organización social.

Un grado de especialización en las formas cerámicas, materias primas y técnicas utilizadas semejante al constatado en las sociedades argáricas puede observarse etnográficamente, por ejemplo, entre las etnias konkomba o kusasi (noreste de Ghana) (Albero et al. 2013; Calvo et al. e.p.). En producciones de tipo doméstico como éstas, dedicadas a la manufactura de cerámica a tiempo parcial, las estrategias de aprendizaje y de transmisión de conocimiento acerca del uso de determinados materiales y técnicas, así como la alta interacción social que existe entre las alfareras, por ejemplo de una misma comunidad o de un grupo étnico, favorecen la obtención de productos relativamente estandarizados en su tecnología (Livingstone-Smith 2000; Gosselain y Livingstone-Smith 2005).

Debe tenerse en cuenta, por tanto, que la existencia de una alta interacción social entre productores y unos sistemas de transmisión del conocimiento y del habitus tecnológico consolidados y estables habría posibilitado el establecimiento de una misma tradición, favoreciendo la consecución de un perfil de artesano relativamente especiali- 
zado. La homogeneidad observada en las prácticas tecnológicas sugiere que los alfareros habrían compartido el mismo concepto de producto estandarizado y que probablemente las cerámicas eran percibidas, conceptualizadas e incorporadas en la práctica social de forma similar. La presencia de conjuntos cerámicos homogéneos y de una tecnología común debió favorecer la creación de vínculos entre determinados grupos sociales, así como definir sus roles y fomentar determinadas formas de identidad (Neupert 2000).

Este último aspecto es especialmente interesante si consideramos que las cerámicas son objetos que están cargados de significados. Precisamente el rol simbólico que las vasijas funerarias pudieron tener en prácticas de comensalidad ha sido recientemente enfatizado como un factor de gran relevancia e influencia en la manufactura de vasijas con unas propiedades formales y tecnológicas homogéneas y en el desarrollo de una cierta especialización en la producción. La aparición de formas asimétricas de organización social habría requerido de un complejo entramado ceremonial y ritual que estimularía la manufactura de cerámicas que contribuyeran a la expresión y exhibición de nuevas formas de comprensión y naturalización de la realidad (Aranda 2010).

Junto a la homogeneidad tecnológica de las muestras analizadas se han documentado igualmente "anomalías" o particularidades dentro de la norma, lo que comienza a ser una característica nada extraordinaria dentro de los conjuntos cerámicos argáricos (Aranda 2010). En el caso del Cerro de San Cristóbal se produce además la coincidencia de que las excepciones registradas en la secuencia de producción dominante se corresponden especialmente con vasijas cerámicas que se asocian a la sepultura 7. Se trata del único enterramiento en urna cerámica del poblado, un tipo de contenedor funerario poco habitual en las comarcas interiores del sureste y completamente desconocido en la Vega de Granada (Tabla 1). Además, las singularidades tecnológicas se asocian a rasgos morfológicos igualmente particulares. Este es el caso de la vasija CSC-7.1, completamente ajena a tipos cerámicos argáricos, de la cerámica CSC-7.2 también diferente a las formas clásicas argáricas, en este caso además encuadrable cronológicamente en momentos tardíos, o de la urna de enterramiento CSC-7.3 que se caracteriza por paredes irregulares en su perfil y grosor, y una forma asimétrica que nos remiten a un perfil de alfarero/a con una menor pericia técnica. El resto de elementos de ajuar, un pendiente/anillo realizado en bronce y una cuenta de collar en hueso, en nada difieren de los habituales ajuares de época argárica.
La documentación de vasijas con rasgos formales y/o tecnológicos diferentes al patrón habitual permite plantear secuencias alternativas de manufactura que son más variables y están basadas en productores poco especializados y en esporádicos episodios de manufactura relacionados muy probablemente con un consumo familiar. Este tipo de cerámicas han sido relacionadas con aspectos diversos del aprendizaje y la socialización (Sánchez Romero 2004, 2008), con la producción de contendores funerarios para individuos infantiles realizados por sus propias madres (Colomer 2005; Albero 2011) o simplemente con producciones domésticas para usos varios (Ayala Juan 1991; Van Berg 1998; Castro Martínez et al. 1999). En el caso específico del Cerro de San Cristóbal, la concentración de las peculiaridades formales y tecnológicas en las vasijas de la sepultura 7 , correspondiente a un enterramiento doble de individuo femenino e infantil, también podría interpretarse en términos de resistencia o rechazo a determinados esquemas normativos y de reivindicación de otras formas de comprensión de la realidad.

En definitiva, el conjunto cerámico estudiado en el presente trabajo muestra una clara bipolaridad. Por una parte, se encuentran los ajuares cerámicos que reproducen formas argáricas clásicas, especialmente vasijas carenadas, tecnológicamente caracterizadas por una secuencia de producción uniforme y relacionada con un perfil de artesano relativamente especializado. Por otra parte, las vasijas de la sepultura 7 que se sitúan en modelos formales y tecnológicos alternativos y en lo que parece ser unas estrategias alfareras basadas en productores poco especializados $\mathrm{y}$ en dinámicas sociales diferenciadas.

Obviamente, lo limitado de la muestra disponible y su restricción a un único contexto funerario no nos permite realizar interpretaciones robustas acerca de los motivos que propiciaron unas determinadas estrategias de producción. Si bien la intención es poder abordar esta cuestión en un futuro, tenemos que aceptar que ello supera los objetivos y posibilidades de este trabajo y exige el análisis de nuevos conjuntos cerámicos de variados contextos y yacimientos, así como una profunda revisión de las bases teóricas aplicadas hasta ahora. En cualquier caso, la información aportada por el Cerro de San Cristóbal a través de los análisis arqueométricos y su correlación con las variables contextuales y morfológicas ha permitido profundizar en la complejidad de las formas de organización de la producción y en los significados de las elecciones formales y tecnológicas desarrolladas por las sociedades argáricas. 


\section{Agradecimientos}

El presente trabajo ha sido realizado en el marco del proyecto de investigación $\mathrm{I}+\mathrm{D}+\mathrm{i}$ El contexto social de consumo de alimentos y bebidas en las sociedades de la Prehistoria Reciente del sur peninsular (HAR200907283).

\section{Notas}

1. Para una descripción detallada de las sepulturas véase Aranda et al. 2012.

2. La preparación de las láminas delgadas fue realizada por el Dr. Romualdo Seva (Unidad de Arqueometría, Universidad de Alicante).

3. Los estudios mediante lámina delgada se han realizado en el Department of Archaeology de The University of Sheffield (UK) con la colaboración del Dr. Peter Day.

4. La molienda de las muestra se ha realizado en el Laboratorio del Departamento de Ciencias de la Tierra de la UIB.

5. Los análisis de DRX se han realizado en el Laboratorio de Propiedades Físicas, Servicios Científicos y Técnicos, Universidad de las Islas Baleares.

6. Este análisis se ha realizado en el servicio de Microscopia de los Servicios Científicos y Técnicos de la Universidad de las Islas Baleares con la supervisión del Dr. F. Hierro.

\section{REFERENCIAS Bibliograficas}

Albero, D. (2011): Caracterización tecnológica, social y adaptación funcional de cerámicas prehistóricas en el Oeste y Sureste de Mallorca (1700-50 BC): aproximación sincrónica y diacrónica a partir del estudio arqueométrico de pastas. Tesis doctoral electrónica. Universidad de Granada, Granada.

Albero, D.; Calvo, M.; Javaloyas, D., García Rosselló, J. (2013): Homología y redes de aprendizaje: una aproximación a la producción de cerámica konkomba (NE Ghana). II Congreso Internacional sobre Estudios Cerámicos: Etnoarqueología y experimentación, más allá de la analogía, Universidad de Granada: 19-21.

Aranda, G. (2001): El análisis de la relación forma-contenido de los conjuntos cerámicos del yacimiento arqueológico del Cerro de la Encina (Granada, España), British Archaeological Reports International Series 927, Archaeopress, Oxford.

Aranda, G. (2004): Craft specialization in pottery production during the Bronze Age in south-eastern Iberia. Journal of Iberian Archaeology, 6: 157-179.

ArAnda, G. (2010): Entre la tradición y la innovación: el proceso de especialización en la producción cerámcia argárica. Menga. Revista de Prehistoria de Andalucía, 1: 77-95.

Aranda, G.; Alarcón, E.; Murillo Barroso, M.; Montero, I.; Jiménez-Brobeil, S.; Sánchez Romero, M.; Rodríguez-Ariza, M.O. (2012): El yacimiento argárico del cerro de San Cristóbal (Ogíjares, Granada). Menga. Revista de Prehistoria de Andalucía, 3: 141-65.

Arnold, D.E. (2000): Does the standardization of ceramic pastes really mean specialization? Journal of Archeaological Method and Theory, 7: 333-357.

Arnold, P.J. (1999): On Typologies, Selection, and Ethnoarchaeology in Ceramic Production Studies. Material Meanings. Critical Approaches to the Interpretation of Material Culture (E. Chilton, ed.), University of Utah Press, Utah: 103-117.

Arteaga, O.; Schubart, H. (2000): Formas de la cerámica argárica de Fuente Álamo. Fuente Álamo. Las excavaciones arquológicas 1977-1991 en el poblado de la Edad del Bronce (H. Schubart, V. Pingel, O. Arteaga, eds.). Consejería de Cultura de la Junta de Andalucía, Sevilla: 99-106.

Ayala Juan, M.M. (1991): El poblamiento argárico en Lorca. Estado de la cuestión. Real Academica Alfonso X el Sabio, Murcia.

Blackman, M.; Stein, G.; Vandivier, P. (1993): The Standardization Hypothesis and Ceramic Mass Production: Technological, Compositional, and Metric Indexes of Craft Specialization at Tell Leilan, Syria. American Antiquity, 58(1): 60-80. 
Budden, S. (2009): Technological signatures of ceramics: a methodology to define and interpret skill and learning strategies. X European Meeting on Ancient Ceramics, London.

Buxeda, J.; Tsantini, E. (2009): Les àmfores ibèriques del derelicte de Cala San Vicenç i la seva contrastació amb les àmfores de la Palaià Polis d'Empúries: Evidències des de la seva caracterització arqueomètrica. El vaixell grec arcaic de Cala San Vicenç (X. Nieto, M. Santos, eds.), Monografies del CASC 7: 373-392.

BuXEDA, J.; MADRID, M. (2009): Sobre un individu de ceràmica grisa monocroma de derelicte de Cala San Vicenç i la seva contrastació amb la producción de la Palaià Polis d'Empúries: La seva caracterització arqueomètrica. El vaixell grec arcaic de Cala San Vicenç (X. Nieto, M. Santos, eds.), Monografies del CASC 7: $347-354$.

Calvo, M.; García Rosselló, J.; Javaloyas, D.; Albero, D. (en prensa): Playing with mud? An ethnoarchaeological approach to children's learning in Kusasi ceramic production. Children, identity and space (M. Sánchez Romero, E. Alarcón García, G. Aranda Jiménez, eds.), SSCIP Monograph Series, Oxbow, Oxford.

Capel, J.; Delgado, R.; PÁrraga, J.; Guardiola, J.L. (1995): Identificación de técnicas de manufactura y funcionalidad de vasijas cerámicas en estudios de lámina delgada. Complutum, 6: 311-318.

Castro, P.V.; Chapman, B.; Gili, S.; Lull, V.; Micó, R.; Rihuete, C.; Sanahuja, M.E. (1993-94): Tiempos sociales de los contextos funerarios argáricos. Anales de Prehistoria y Arqueología, 9-10: 77-106.

Castro, P.V.; Chapman, B.; Gili, S.; Lull, V.; Micó, R.; Rihuete, C.; Risch, R.; Sanahuja, M.E. (1999): Proyecto Gatas 2. La dinámica arqueoecológica de la ocupación prehistórica. Consejería de Cultura de la Junta de Andalucía, Sevilla.

Cau Ontíveros, M.A.; Day, P.M.; Montana, G. (2002): Secondary calcite in archaeological ceramics: evaluation of alteration and contamination processes by thin section study. Modern Trends in Scientific Studies of Ancient Ceramics (V. Kilikoglou, A. Hein, Y. Maniatis, eds.), BAR Internat. Series 1011, Archaeopress, Oxford: 9-18.

Chung, F. (1974): Quantitative interpretation of X-ray diffraction patterns: Matrix flushing method of quantitative multicomponent analisys. Journal of Applied Crystallography, 7: 519-525.

Colomer, E. (2005): Cerámica prehistórica y trabajo femenino en el Argar: una aproximación desde el estudio de la tecnología cerámica. Arqueología y Género (M. Sánchez Romero, ed.), Universidad de Granada, Granada: 177-219.

Comodi, P.; Zanazzi, P.F. (2000): Structural thermal behavior of paragonite and its dehydroxylate: a hightemperature single-crystal study. Physics and Chemistry of Minerals, 27(6): 377-385.

Costin, C. (1991): Craft Specialization: Issues in Defining, Documenting, and Explaining the Organizations of Production. Advances in Archaeological Method and Theory, 3: 1-56.

Costin, C. (2000): The use of Ethnoarchaeology for the Archaeological Study of Ceramic Production. Journal of Archaeological Method and Theory, 7(4): 377-403.

Costin, C. (2005): Craft production. Handbook of Archaeological Method (H. Maschner, C. Chippindale, eds.), Altamira Press, Lanham: 1084-1107.

Contreras, F.; Capel, J.; Esquivel, J.A.; Molina, F.; De la Torre, F. (1987-88): Los ajuares cerámicos de la necrópolis argárica de la Cuesta del Negro (Purullena, Granada). Avance al estudio analítico y estadístico. Cuadernos de Prehistoria de la Universidad de Granada, 12-13: 135-156.

Contreras, F.; CÁmara, J.A. (2000). La cerámica. Proyecto Peñalosa. Análisis histórico de las comunidades de la Edad del Bronce del piedemonte meridional de sierra Morena y depresión Linares-Bailén (F. Contreras, ed.), Consejería de Cultura, Junta de Andalucía, Sevilla: 77-128.

Cuadrado, E. (1950): Utiles y armas de El Argar. Ensayo de tipología. I Congreso Nacional de Arqueología. Cartagena: 7-28.

Cuomo Di Caprio, N.; Vaughan, S. (1993): An experimental study in distinguishing grog (Chamotte) from argillaceous inclusions in ceramic thin sections. Archeomaterials, 7(1): 21-40.

Dietler, M.; Herbich, I. (1998): Habitus, techniques, style: an integrated approach to the social understanding of material culture and boundaries. The Archaeology of Social Boundaries (M. Stark, ed.), Smithsonian, Washington: 232-263.

Dobres, M.; Hoffman, C. (1994): Social agency and the dynamics of prehistoric technology. Journal of Archaeological Method and Theory, 1(3): 211-258.

Drebushchak, V.; Mylnikova, L.; DrebushchaK, T.; Boldyrev, V. (2005): The investigation of ancient pottery: Application of thermal analysis. Journal of Thermal Analysis and Calorimetry, 82: 617-626.

García LóPez, M.M. (1992): La Bastida de Totana: estudio de materiales arqueológicos inéditos. Universidad de Murcia, Murcia. 
García Rosselló, J.; Calvo Trias, M. (2006): Análisis de las evidencias macroscópicas de cocción en la cerámica prehistórica una propuesta para su estudio. Mayurqa, 31: 83-112.

Gosselain, O.; Livingstone-Smith, A. (2005): The source clay selection and processing practices in Sub-Saharian Africa. Pottery Manufacturing Processes: Reconstitution and Interpretation (A. Livingstone, D. Bosquet, R. Martineau, ed.), BAR International Series 1349, Archaeopress, Oxford: 33-47.

Hurcombe, L. (2007): A Sense of Materials and Sensory Perception in Concepts of Materiality. World Archaeology, 39(4): 532-545.

IGME (1980) Mapa geológico de España 1: 50.000, Padul. Ministerio de Industria y Energía, Madrid.

Jover Maestre, F.J.; López Padilla, J.A. (2009): La cerámica argárica de San Antón y Laderas del Castillo a partir de la colección Furgús. En los confines del Argar. Una cultura de la Edad del Bronce en Alicante (M. Hernández Pérez, J. Soler Díaz, J.A. López Padilla, eds.), MARQ Museo Arqueológico de Alicante, Alicante: 100-109.

Lemonnier, P. (1993): Introduction to Technological choices: Transformation in Material Cultures since the Neolithic. Routledge. London.

Linares, J., Huertas, F., CAPel, J. (1983): La arcilla como material cerámico: características y comportamiento. Cuadernos de Prehistoria de la Universidad de Granada, 8: 479-490.

Livingstone-Smith, A. (2000): Processing clay for pottery in northern Cameroon: Social and technical requirements. Archaeometry, 42: 21-42.

Longacre, W.A. (1999): Standardization and Specialization: what's the link? Pottery and people. A dynamic interaction (J. Skibo, G. Feinman, eds.), The University Utah Press, Utah: 44-58.

Lull, V. (1983): La cultura del argar. Un modelo para el estudio de las formaciones sociales prehistóricas. Crítica, Barcelona.

Mainman, A. (1982): Studies of Anglo-Saxon pottery from Canterbury. Current research in ceramics: Thinsection studies (I. Freestone, C. Johns, T. Potter, eds.), British Museum Occasional Paper 32, Londres: 93-100.

Martínez Rodríguez, A.; Ponce García, J.; Ayala Juan, M.M. (1999): Excavaciones de urgencia del poblado argárico de Los Cipreses, Lorca. Años 1992-93. Memorias de Arqueología, 8: 156-182.

Maritan, L.; Mazzoli, C.; Freestone, I. (2007): Modelling changes in mollusc shell internal microstructure during firing: implications for temperature estimation in shell bearing pottery. Archaeometry, 49(3): 529-541.

Martín, J.D. (2004): Using XPowder: A software package for Powder X-Ray diffraction analysis. www.xpowder. com

Matthew, A.J.; Woods, A.J.; Oliver, C. (1991): Spots before the eyes: new comparison of charts for visual percentage estimation in archaeological material. British Museum Occasional Paper, 81: 211-264.

Milà, M.S.; Arana, R.; Cámara, J.A.; Contreras, F. (2007): La cerámica argárica de Peñalosa. Un estudio arqueométrico. As Idades do Bronze e do Ferro na Península Ibérica. Actas del IV Congresso de Arqueología Peninsular (Faro, 14 a 19 de Setembro de 2004), (J. Morín, D. Urbina, N. Ferreira, eds.), Universidade do Algarve, Braga. 171-184.

MilÀ, M.S.; BuXedA, J.; AlíAs, A.; AranA, R. (2000): Caracterización arqueométrica de cerámicas argáricas del yacimiento de Los Cipreses (Lorca). Cadernos del Laboratorio Xeolóxico de Laxe, 25: 399-402.

Neupert, M.A. (2000): Clays of Contention: An ethnoarchaeological Study of Factionalism and Clay Composition. Journal of Archaeological Method and Theory, 7(3): 249-272.

Ruiz-GÁlvez, M. (1977): Nueva aportación al conocimiento de la cultura de El Argar. Trabajos de Prehistoria, 34: $85-110$.

Rye, O.S. (1981): Pottery Technology: Principles and Reconstruction. Traxacum, Washington D.C.

SÁnchez Romero, M. (2004): Children in southeast of Iberian Peninsula during Bronze Age. EthnographischArchäologische Zeitschrift, 47: 377-387.

SÁnchez Romero, M. (2008): Childhood and the Construction of Gender Identities through Material Culture. Childhood in the Past, 1: 17-37.

Schiffer, M.B.; SkiBo, J.M. (1987): Theory and experiment in the study of technological change. Current Anthropology, 28: 595-622.

Schubart, H.; Pingel, V.; Arteaga, O. (2000): Fuente Álamo. Las excavaciones arqueológicas 1977-1991 en el poblado de la Edad del Bronce. Arqueología Monografías, Consejería de Cultura de la Junta de Andalucía, Sevilla. 
Schuhmacher, T.X. (2003). Die Sidedlungskeramik der Grabungen 1985-1991. Iberia Archaeologica, 4: 15-296.

Sinopoli, C.M. (1988): The Organization of Craft Production at Vijayanagara, South India. American Anthropologist, 90(3): 580-597.

SIRET, E.; SiRET, L. (1890): Las primeras edades del metal en el sudeste de España. Resultados obtenidos en las excavaciones hechas por los autores desde 1881 a 1887. Barcelona.

StARK, B.L. (1995): Problems in Analysis of Stardardization and Specialization in Pottery. Ceramic Production in the American Southwest (B. Mills, P. Crown, eds.), The University of Arizona Press, Tucson: 231-276.

Van Berg, P.L. (1998): La Collection Siret à Bruxelles 2. La Céramique de la Culture d'el Argar (2300-1600 avant notre ère). Musées Royaux d'art et D'histoire, Bruxulles.

Velde, B.; Druc, I. (1999): Archaeological Ceramic Materials: Origin and Utilization. Springer, Berlin.

WhITBREAD, I. (1986): The characterization of argillaceous inclusions in ceramic thin sections. Archaeometry, 28: 79-88.

WhitBread, I. (1995): Greek Transport Amphorae: A Petrological and Archaeological Study. Fitch Laboratory Occasional Paper, 4. British School at Athens, Athens. 